\title{
A New Combinational Terminology for Geothermal Systems
}

\author{
Mohammad Rezaie, Hamid Aghajani* \\ Faculty of Mining, Petroleum and Geophysics, Shahrood University of Technology, Shahrood, Iran \\ Email: "haghajani@shahroodut.ac.ir, "aghajani_hamid@yahoo.com
}

Received September 27, 2012; revised November 2, 2012; accepted December 5, 2012

\begin{abstract}
A geothermal resource can be defined as a reservoir inside the Earth from which heat can be extracted economically. Geothermal resources are classified on the basis of different aspects, such as heat source, heat transfer, reservoir temperature, physical state, commercial utilization and geological settings. Unfortunately most of the current classifications that are used for geothermal systems are not complete. So, a combinational terminology of geological and temperature-based classifications would be more complete. This terminology can explain all geological situations, temperature and physical state of geothermal reservoir altogether. According to geological settings, in combinational terminology (from left to right), the class of geothermal resource's name would be placed at first, then the physical state of reservoir (Liquid-dominated or Two-phase or Vapor-dominated) would be written and finally the class of the geothermal reservoir which is related to its temperature, is written.
\end{abstract}

Keywords: Geothermal Systems; Classification; Combinational Terminology; Geothermal Resource; Component

\section{Introduction}

Geothermal energy is a clean and renewable source of energy that recently has been used. Geothermal energy is the natural heat which is stored in the rocks and water within the Earth [1]. And a geothermal resource can be defined as a reservoir inside the Earth from which heat can be extracted economically and utilized for generating electric power or any other suitable industrial, agricultural or domestic application [2].

Resource classification has a key role in the characterization, assessment and development of energy resources, including geothermal energy, because Stakeholders at all levels of government, within the geothermal industry, and among the general public need to be able to use and understand consistent terminology when addressing geothermal resource issues [3]. Geothermal resources are classified on the basis of different aspects, such as heat source, heat transfer, reservoir temperature, physical state, commercial utilization and geological settings $[3,4]$.

However, most of time, geothermal resources are classified and got a name with respect to their geological setting [2,4-7] and their temperature [8-11].

Classification of geothermal systems according to their nature and geological settings is very important why geologic setting of a geothermal system has a fundamental effect on the potential temperature, fluid composition,

${ }^{*}$ Corresponding author. and reservoir characteristics [3]. There are some similarities among current different methods for naming and classification of geothermal systems on the bases of their geology. There are also some differences.

Classification of geothermal systems according to their temperature is economically important why our final target is extraction of heat from geothermal reservoir. But there is no general agreement on the temperature ranges used and Classification of a geothermal resource by its reservoir fluid temperature is ambiguous [12].

Unfortunately, almost all of geothermal classifications and terminologies do not encompass both geology and temperature. In this paper we will propose a combinational terminology for geothermal systems that cover both of geology and temperature which are related to them. For this reason first we will briefly explain the geology of geothermal systems, then we will classify them on basis of their geological settings. Later, we will review some of classifications of geothermal systems based on their temperature and choose one of them. Then, we propose a combinational terminology for geothermal systems. Finally, we will term Berlín geothermal field by this methodology as a case study.

\section{Geology of Geothermal Systems}

Geothermal field is defined geographically, usually indicating an area of geothermal activity on the surface of the earth. In cases which there is no surface activity, this 
term may be used to indicate the area at the surface corresponding to the geothermal reservoir below. Geothermal system refers to all parts of the hydrological system involved, including the recharge zone, all subsurface parts and the outflow of the system. Geothermal reservoir indicates the hot and permeable part of a geothermal system that may be directly exploited. For spontaneous discharge to be possible, geothermal reservoirs must also be pressurized, either artesian or through boiling [4].

A geological setting which a geothermal reservoir is to be found in it can vary widely. The largest geothermal fields currently under exploitation occur in rocks that range from limestone to shale, volcanic rock and granite. Volcanic rocks are probably the most common single rock type in which reservoirs occur. Rather than being identified with a specific lithology, geothermal reservoirs are more closely associated with heat flow systems [13]. Geothermal systems are commonly associated with areas of young Tectonism and volcanism (mainly along active plate margins and interpolate hot spots) than stable cratonic regions [1]. An ideal geothermal system (Figure 1) would consist of: 1) a large source of heat, 2) a reservoir which accumulates heat, 3) a barrier (cap rock) to hold the accumulated heat, and 4) groundwater (working fluid) for transporting the heat.

\section{Classification of Geothermal Resources on the Bases of Their Nature and Geology}

Geothermal systems can be subdivided, based on their heat transfer regimes and geological settings, into two broad categories: 1) Convective Systems, 2) Conductive Systems [6].

Convective geothermal systems are determined by natural circulation of working fluid [14]. These convective systems have two basic classes' convective systems depending on the source of the thermal energy: volcanic and non-volcanic. A volcanic convective system drives its thermal energy from a convecting magma body [7]. The heat sources for such systems are hot intrusions or magma. They are most often situated inside, or close to, volcanic complexes such as calderas, most of them at plate boundaries but some in hot spot areas. Permeable fractures and fault zones mostly control the flow of water in volcanic systems [4]. A non-volcanic convective system drives its thermal energy from meteoric water that has heated up by deep circulation in high heat flow areas of the earth; there is no magma body associated with such a system [7].

Conductive geothermal systems can be characterized by a thermal regime due to conduction alone. The working fluid can be present or should be supplied in these systems. Convective circulation is prohibited because of low temperature contrast or low permeability [14]. There are three classes in these systems: 1) Sedimentary systems, 2) Geo-pressured systems, 3) Hot dry rock (HDR) or enhanced (engineered) geothermal systems (EGS).

Sedimentary systems could be found in many of the major sedimentary basins of the world. These systems become to existence because of the occurrence of permeable sedimentary layers at great depths $(>1 \mathrm{~km})$ and

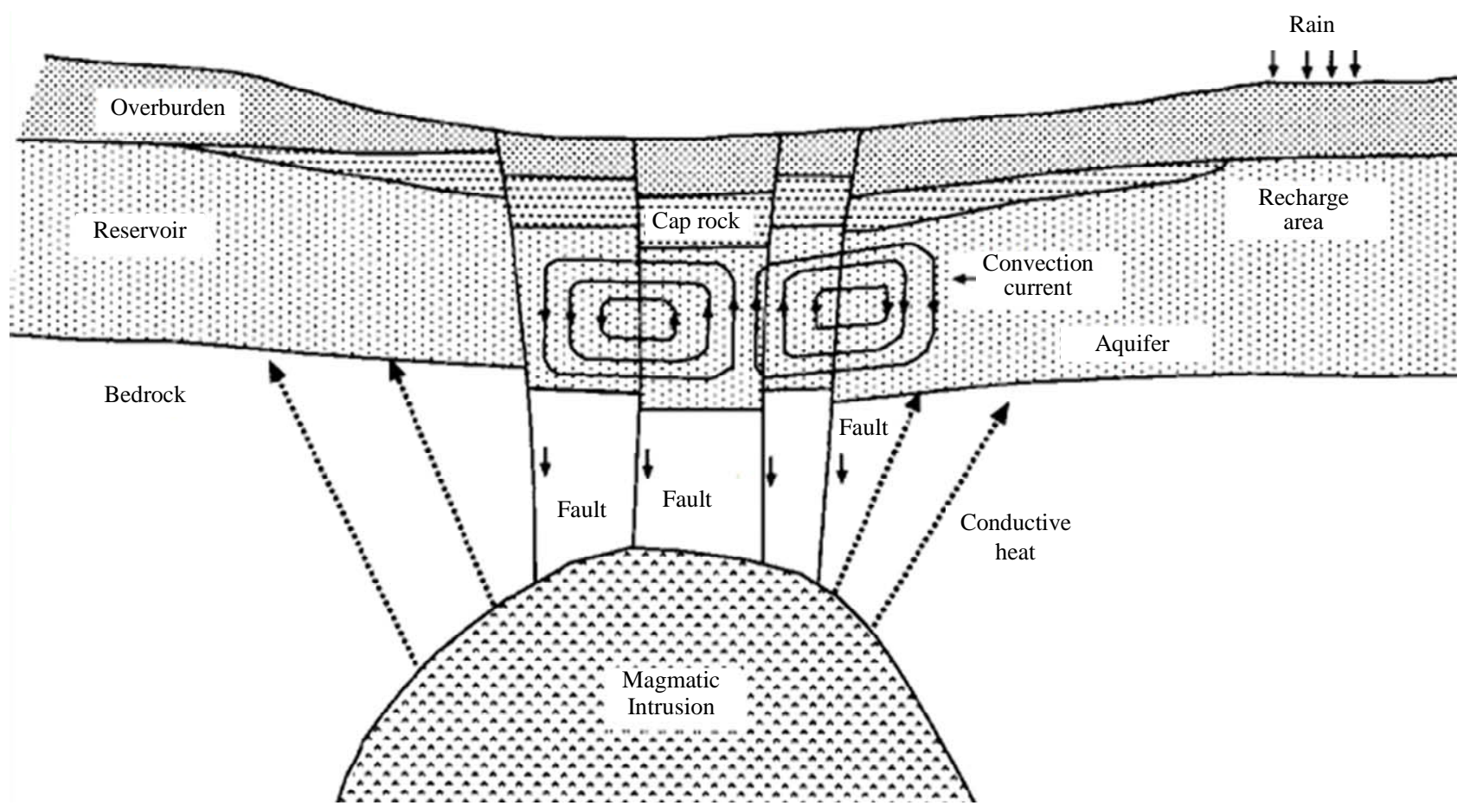

Figure 1. A conceptual model of an ideal geothermal system [1]. 
above average geothermal gradients $\left(>30^{\circ} \mathrm{C} / \mathrm{km}\right)$ (Figure 2). These systems are conductive in nature rather than convective, even though fractures and faults play a role in some cases [4]. The sedimentary systems could be seen in the Madison Formation of North Dakota, South Dakota, Montana and Wyoming area of the northern United States and the Pannonian Basin of central Europe where it has been used extensively in Hungary [15].

Geo-pressured systems occur in basin environments where deeply buried fluids contained in permeable sedimentary rocks which are warmed in a normal or enhanced geothermal gradient by their great burial depth. The fluids are tightly confined by surrounding impermeable rock and their pressure is much greater than hydrostatic [15].

Hot dry rock (HDR) or enhanced (engineered) geothermal systems (EGS) are volumes of rock that have been heated up by volcanism or abnormally high heat flow. They have low permeability or are virtually impermeable. Therefore, they cannot be exploited easily. An EGS is defined as a man-made reservoir which created by artificial fracturing of impermeable or very low permeable rock through wells. Our classification based on heat transfer regimes and geological settings is summarized in Table 1.

\section{Classification on the Bases of Temperature and Thermodynamic}

Another important issue in assessing and terminology of geothermal systems is temperature properties of geother- mal reservoir. So it must have a key role in classification of geothermal systems.

Geothermal systems and reservoirs can be classified on the basis of their temperature into two, three or more classes. In each case the temperature/enthalpy boundaries are significant in either a thermodynamic or an economic utilization context [3] (Figure 3). For example geothermal systems and reservoirs are classified on the basis of their enthalpy into Low-enthalpy geothermal systems and High-enthalpy geothermal systems. Low-enthalpy geothermal systems which their reservoir fluid enthalpies are less than $800 \mathrm{~kJ} / \mathrm{kg}$ and corresponding to temperatures less than about $190^{\circ} \mathrm{C}$. High-enthalpy geothermal systems which their reservoir fluid enthalpies are greater than $800 \mathrm{~kJ} / \mathrm{kg}$ [17]. And in USGS assessments, geothermal systems are divided into three temperature classes: low-temperature $\left(<90^{\circ} \mathrm{C}\right)$, moderate-temperature $\left(90^{\circ} \mathrm{C}\right.$ to $\left.150^{\circ} \mathrm{C}\right)$, and high-temperature $\left(>150^{\circ} \mathrm{C}\right)[5,11,18]$. There is another classification that has proposed by Lee (2001). He has proposed that geothermal resources can be classified as low, medium and high quality resources with reference to their specific energy indices.

Sanyal (2005) has proposed a classification in which geothermal resources can be classified into seven categories based on temperature: non-electrical grade $\left(<100^{\circ} \mathrm{C}\right)$, very low temperature $\left(100^{\circ} \mathrm{C}\right.$ to $\left.<150^{\circ} \mathrm{C}\right)$, low temperature $\left(150^{\circ} \mathrm{C}\right.$ to $\left.190^{\circ} \mathrm{C}\right)$, moderate temperature $\left(190^{\circ} \mathrm{C}\right.$ to $<230^{\circ} \mathrm{C}$ ), high temperature $\left(230^{\circ} \mathrm{C}\right.$ to $\left.<300^{\circ} \mathrm{C}\right)$, ultrahigh temperature $\left(>300^{\circ} \mathrm{C}\right)$, and steam fields (approximately $240^{\circ} \mathrm{C}$ with steam as the only mobile phase).

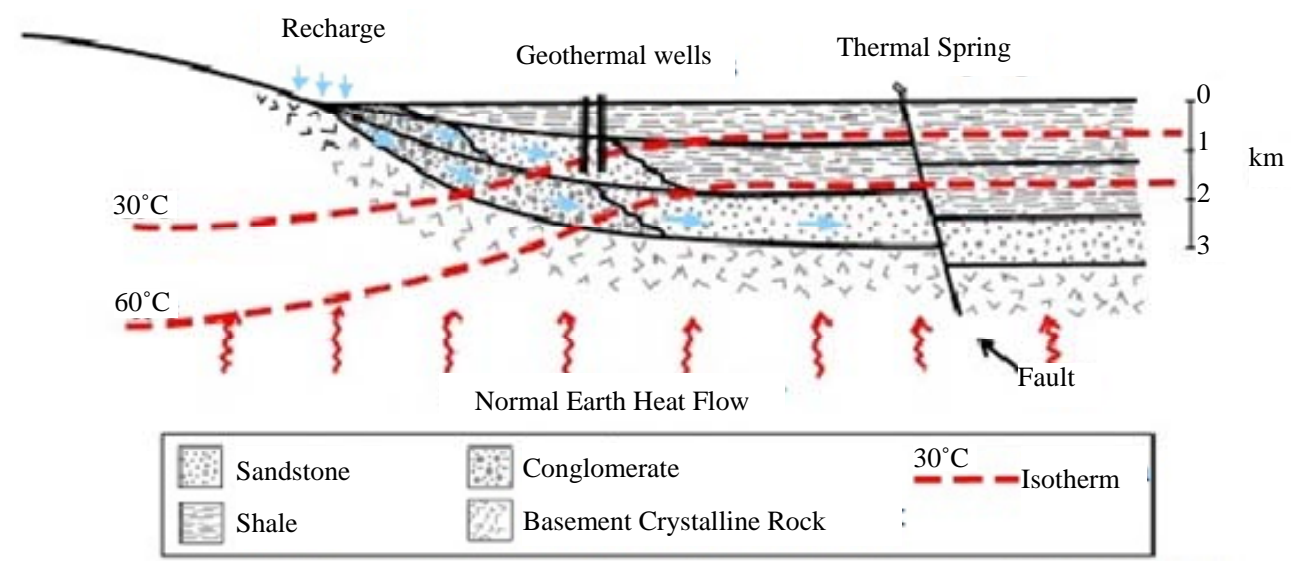

Figure 2. Sedimentary geothermal system [16].

Table 1. Geothermal resource types.

\begin{tabular}{lcc}
\hline According to heat transfer regimes & Convective & Conductive \\
& Volcanic & Sedimentary systems \\
According to geological settings & & Geo-pressured systems \\
& Non-Volcanic & HDR or EGS systems \\
\hline
\end{tabular}




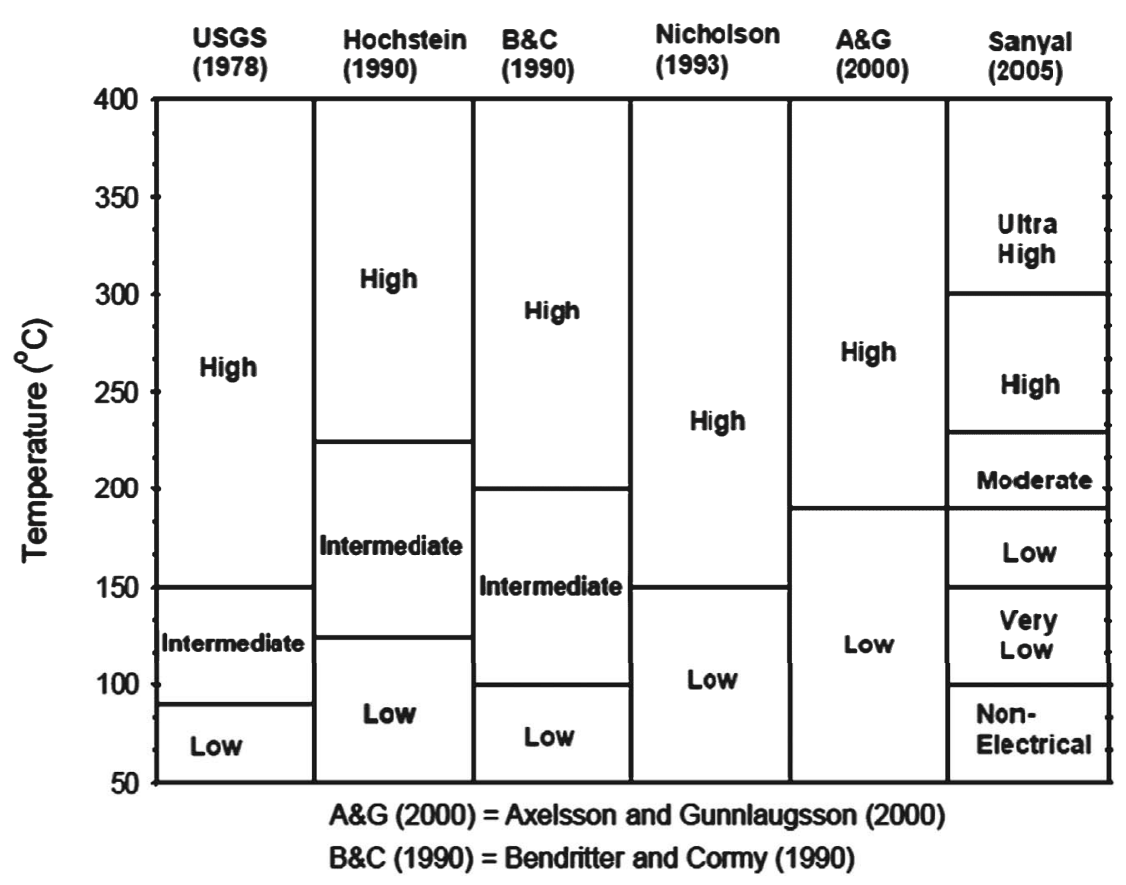

Figure 3. Classifications of geothermal resources by temperature [3].

Here we will use Synal's classification in our combinational terminology because temperature ranges are smaller and also this classification is based not only on temperature but also according to a set of additional attributes that are important for practical utilization of geothermal energy.

\section{Combinational Terminology for Geothermal Resources}

Unfortunately most of current classifications that are used for geothermal systems are not complete. So a combinational terminology from geological and temperature based classifications can be more complete. This terminology can explain all geological situations, temperature and physical state of geothermal reservoir altogether. At the beginning, we have to determine classes of a geothermal system according to its temperature and geological setting. The physical state of the fluid that exists in it should be determined, too. According to geological settings, in combinational terminology (from left to right), the class of geothermal resource's name from Table $\mathbf{1}$ would be placed at first, then the physical state of reservoir (Liquid-dominated or Two-phase or Vapor-dominated) would be written and finally the class of the geothermal reservoir which is related to its temperature from last column in Figure 3, is written (Figure 4).

Suppose that there is a volcanic geothermal system and is vapor-dominated and the temperature of its reservoir is about $260^{\circ} \mathrm{C}$. According to the combinational terminology we can call it as: volcanic vapor-dominated high temperature geothermal system. It is clear that this

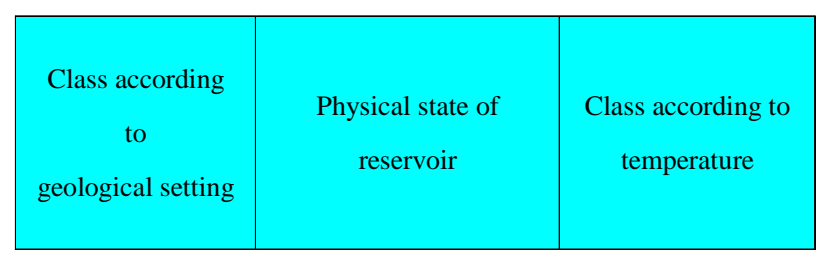

Figure 4. combinational term for geothermal resources.

name encompasses geology, physical state and temperature of this geothermal system and can be a good definition for this geothermal system.

This terminology encompasses both the fundamentally geological nature of geothermal resources and almost the practical technological and economic aspects of resource exploitation while remaining understandable to the broad community of non-experts and experts.

\section{Case study: Berlín Geothermal Field, El Salvador}

The Berlín geothermal field is one of the geothermal fields in El Salvador. It is located $110 \mathrm{~km}$ east of San Salvador, the capital City, in the District of Usulutan, near Berlín City. This geothermal field is located on the northern flank of the Berlín-Tecapa volcanic complex, inside a system of faults in the southern part of the eastwest oriented Central American graben. The Berlín-Tecapa volcanic complex is formed by the caldera of the Berlín strata volcano, and composed of a series of peripheral volcanic cones that expelled andesitic lava and scoria that emerged around the craters in the southeast part of the old Berlín volcano caldera [19]. According to 
Table 2. Classification of Berlín geothermal system by different methods.

\begin{tabular}{cc}
\hline Classification & Class \\
\hline Geology & Volcanic geothermal system \\
Physical state of water & Liquid-dominated geothermal system \\
USGS (1987) & High temperature geothermal system \\
Enthalpy [17] & High enthalpy geothermal system \\
Sanyal (2005) & High temperature geothermal system \\
Combinational terminology & Volcanic liquid dominated high temperature geothermal system \\
\hline
\end{tabular}

available information, the field's heat resource is located underneath the Berlín caldera with an up flow coming from the south part of the caldera; the hot fluid flows laterally north/northeast along the graben faults. The Berlín geothermal field is a liquid-dominated system with temperatures in the range of $280^{\circ} \mathrm{C}-300^{\circ} \mathrm{C}$ according to measured temperatures in the production wells. The enthalpy varies from 1200 to $1400 \mathrm{~kJ} / \mathrm{kg}$, with a steam fraction of $20 \%-30 \%$ at 11.5 bars, a separation pressure. The production wells in the Berlín geothermal field have been drilled to a depth between 1000 and $2600 \mathrm{~m}$, and the reinjection wells to a depth of $500-2500 \mathrm{~m}$. The elevation of the Berlín geothermal field ranges between $445 \mathrm{~m}$ a.s.l. in the reinjection area and $1080 \mathrm{~m}$ a.s.l. in the production area [20]. So by this information and according to this paper, we can classify Berlín geothermal system (Table 2). So according to combinational terminology, we can call Berlín geothermal system as a volcanic liquid dominated high temperature geothermal system. This name can explain the Berlín geothermal field, briefly and encompasses geology, physical state and temperature of this geothermal system which are important in assessing it.

\section{Conclusion}

Terminology of a geothermal system is very important in assessment of geothermal resources. The terminology must be understandable and reflects geology and economical aspect of the geothermal system. Temperature has a key role in economy of geothermal resources. Therefore, it is used for classification and terminology of geothermal systems. Current terms and classifications which are used for geothermal systems are not comprehensive and so not encompass geology and temperature of geothermal resources. So a combinational terminology can be a good substitute for them. This new terminology constitutes from three parts, from left to right, geological class of geothermal system (from Table 1), physical state of pore water in reservoir, and temperature class of geothermal system (from Figure 3). This terminology looks more comprehensive.

\section{REFERENCES}

[1] M. A. Meju, "Geoelectromagnetic Exploration for Natural Resources: Models, Case Studies and Challenges," Surveys in Geophysics, Vol. 23, No. 2-3, 2002, pp.133205. doi:10.1023/A:1015052419222

[2] H. Gupta and S. Roy, "Geothermal Energy: An Alternative Resource for the 21st Century,” Elsevier, Amsterdam, 2007.

[3] C. F. Williams, M. J. Reed and A. F. Anderson, "Updating the Classification of Geothermal Resources," Proceedings of Thirty-Sixth Workshop on Geothermal Reservoir Engineering, Stanford, 31 January-2 February 2011.

[4] K. Saemundsson, G. Axelsson and B. Steingrímsson "Geothermal Systems in Global Perspective," Short Course on Surface Exploration for Geothermal Resources, El Salvador, 2009.

[5] D. E. White and D. L. Williams, "Assessment of Geothermal Resources of the United States,” US Geological Survey Circular 726, 1975, p. 155.

[6] L. Rybach, "Geothermal Systems, Conductive Heat Flow, Geothermal Anomalies,” John Wiley \& Sons Ltd., New York, 1981.

[7] S. K. Sanyal, "Future of Geothermal Energy," Proceedings of Thirty-Fifth Workshop on Geothermal Reservoir Engineering, Stanford, 12-14 December 2010, pp. 1-3.

[8] G. Bödvarsson, "Physical Characteristics of Natural Heat Sources in Iceland," Proceeding of UN Conference on New Sources of Energy, Vol. 2, 1964, pp. 82-89.

[9] L. P. J. Muffler and R. Cataldi, "Methods for Regional Assessment of Geothermal Resources," Geothermics, Vol. 7, No. 2-4, 1978, pp. 53-89. doi:10.1016/0375-6505(78)90002-0

[10] S. K. Sanyal, "Classification of Geothermal Systems; A Possible Scheme,” Proceedings of Thirtieth Workshop on Geothermal Reservoir Engineering, Stanford University, Stanford, 31 January-2 February 2005, pp. 85-88.

[11] C. F. Williams, M. J. Reed and R. H. Mariner, "A Review of Methods Applied by the US Geological Survey in the Assessment of Identified Geothermal Resources," US Geological Survey Open-File Report 1296, 2008.

[12] K. C. Lee, "Classification of Geothermal Resources by Energy,” Geothermics, Vol. 30, No. 4, 2001, pp. 431-442. doi:10.1016/S0375-6505(00)00056-0

[13] A. Manzella, "Geophysical Methods in Geothermal Ex- 
ploration (Lecture Notes),” Italian National Research Council, International Institute for Geothermal Research, Pisa, 2000.

[14] H. Wibowo, "Spatial Data Analysis and Integration for Regional-Scale Geothermal Prospectivity Mapping, West Java, Indonesia,” Master's Thesis, International Institute for Geo-Information Science and Earth Observation Enschede, Enschede, 2006.

[15] J. W. Lund, "Characteristics, Development and Utilization of Geothermal Resources," GHC Bulletin, Vol. 28, No. 2, 2007, pp. 1-9.

[16] D. N. Anderson and J. W. Lund, Eds., "Direct Utilization of Geothermal Energy: A Technical Handbook,” Special Report No. 7, Geothermal Resources Council, Davis, 1979. doi:10.2172/6707209

[17] G. Axelsson and E. Gunnlaugsson, "Geothermal Utiliza- tion, Management and Monitoring, in Long-Term Monitoring of High- and Low-Enthalpy Fields under Exploitation,” World Geothermal Congress: Short Course, Morioka, 2000, pp. 3-10.

[18] L. P. J. Muffler, “Assessment of Geothermal Resources of the United States," US Geological Survey Circular Report 790, 1979.

[19] H. Correia, H. Jacobo, F. Castellanos, J. Tenorio, S. Handal and P. Santos, "Synthesis of Geo-Scientific Information of a Conceptual Model of Berlín Geothermal Field,” CEL, 1996.

[20] V. A. Rodríguez, "Analysis of Temperature and Pressure Measurements and Production Data for Berlín Geothermal Field," Geothermal Training in Iceland, UNU-GTP, Iceland, 2005, pp. 297-332. 